\title{
Being an editor
}

\author{
Saul Goldenberg \\ Editor-in-Chief, Acta Cirurgica Brasileira
}

What is it really to be a Brazilian scientific journal editor?

I would like to transmit to others my twenty-two-year experience in this office, during which period I learned a lot.

When I decided to be a journal editor I had a very objective aim, and a specific target - Experimental Surgery. The choice of the specific area of Experimental Surgery was fundamental. I coordinated the M.S and Ph.D Programs in Surgical Operative Technique of the Federal University of Sao Paulo (UNIFESP) from 1982 to 1997.

Dissertations were concluded and published in journals of the clinical area. There was no clear cut limit separating clinical articles from experimental ones. To this purpose, I decided to create a journal which specifically published articles on surgical investigation, especially in Experimental Surgery. This was a new experience because there was no such publication with these characteristics. At first, I decided to name it Paulista Acta Cirurgica in honor of the then Paulista School of Medicine and the state of Sao Paulo. However, I realized the journal should be national and not regional. Thus, Acta Cirurgica Brasileira was born and became the official journal of Brazilian Society for the Development of Surgical Research (SOBRADPEC) that has 23 regional offices in the country.

I did my best to learn the office of an editor. At the beginning, it was difficult but, with the passing of time, I started to enjoy the work. I attended many courses offered by Brazilian Association of Scientific Editors (ABEC) and followed closely the instructions of the International Committee of Editors of Medical Journals (www.icmje.org).

I also followed the determinations of Scientific Eletronic Library Online (SciELO), National Research Council (CNPq) and Sao Paulo State Foundation for Research (FAPESP) which evaluated and approved our journal. The journal was also evaluated by Medline/PubMed, Embase, Scopus and ISI (Thomson Reuters), obtaining a high rank from Coordination for the Improvement of Higher Education Personnel (CAPES) of the Brazilian Ministry of Education.

The selection of members for the Editorial Board and Scientific Committee was very important, as well as the constant care with printing quality and illustrations.

From the very beginning, I tried to adopt the conventional norms for scientific publications and the time between receiving the article and its publication in the journal was the quickest possible.

The accreditation by SciELO and Medline's indexation increased the journal's accessibility and visibility. The journal is firmly established and fully recognized by its international peers. I am sure that constant dedication and diligence were important constituents in the attainment of the journal's objectives. I thank all the manifestations of support received from the beginning of the publication and the authors for sending their articles. I would also like to thank National Research Council (CNPq) for its financial support, the Editorial Board and the referees.

From 1986 to 2001 the journal was published each trimester. From 2002 on it became bimonthly, maintaining its regularity and periodicity. The Journal received an average of 14 original articles $(85 \%)$ for each publication.

In fact, I learned a lot with the whole experience which made me warn national authors, especially those who are negligent and undisciplined. Instructions to authors are always objective and easily accessed on the Internet, besides being published in the journal. I have to confess that sometimes they are not quite observed.

Some national authors insist on disregarding the journal's norms, even in articles of significant scientific content. The return to the sender of articles which are not in accordance with the journal's rules is constant, especially those related to bibliographical references. The same occurs with the consultation of the Health Sciences Descriptors (DeCS). We have warned authors that disregard in relation to descriptors / key words in the DeCS/Mesh make their articles inaccessible (http://decs.bvs.br).

After the journal was indexed by Medline, I decided to publish the articles in English, because I think it is the international scientific language. We also hired an English language consultant to help authors with their English. Sometimes illustrations are sent with no due care to be published. There is also some negligence concerning nomenclature/terminology. Sometimes, Brazilian authors are not cited, including in articles published in the journal. Sometimes, authors send their articles without consulting SciELO and Medline/PubMed and in need of a careful revision. This is the final catharsis of an editor who aims at excellence.

Last of all, I wish to pass a message to young editors: To edit high quality scientific journals in Brazil one has to be moved by PASSION, INVOLVEMENT and RESPONSIBILITY toward their readers!

*This is a copy of the page "Arquivo de Notícias das Coordenadorias", published on 07/01/2008 by Brazilian Association of Scientific Editors ABEC http://www.abesbrasil.org.br, under the title "História resumida da Acta Cirúrgica Brasileira" (Condensed history of Acta Cirurgica Brasileira) 